\title{
Cyclosporin treatment for rheumatoid arthritis: a placebo controlled, double blind, multicentre study
}

\author{
A W A M VAN RIJTHOVEN, ${ }^{1}$ B A C DIJKMANS ${ }^{2}$ H S GOEI THE, ${ }^{3}$
} J HERMANS, ${ }^{4} \mathrm{Z}$ L M B MONTNOR-BECKERS, ${ }^{1} \mathrm{P}$ C J JACOBS, ${ }^{3}$ AND A $\mathrm{CATS}^{2}$

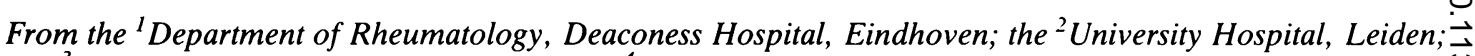
the ${ }^{3}$ De Wever Hospital, Heerlen; and the ${ }^{4}$ Department of Medical Statistics, University, Leiden, The ${ }_{\sigma}^{\omega}$ Netherlands

SUMMARY The efficacy and safety of cyclosporin for patients with rheumatoid arthritis (RA) were assessed in a six month double blind, placebo controlled, multicentre study. The initial $\tilde{N}^{\mathrm{N}}$ dosage of the drug was $10 \mathrm{mg} / \mathrm{kg}$ daily for two months. There were many discontinuations in both음 the cyclosporin group (eight out of 17) and the placebo group (six out of 19). Of the patients whocompleted the six months of therapy, those who had received cyclosporin showed a significant $\mathbb{D}_{\mathbb{D}}$ improvement in the number of swollen joints, the Ritchie articular index, and pain at active $\frac{\overrightarrow{\mathbb{D}}}{\mathrm{D}}$ movement and at rest, compared not only with their condition at the start of the study, but also $\frac{3}{8}$ with the end results of the placebo group. Major adverse reactions to the drug were $\stackrel{\mathbb{D}}{-}$ gastrointestinal disturbances and nephrotoxicity, which were probably due to the relatively high $\overrightarrow{0}$ dosages of cyclosporin given in combination with non-steroidal anti-inflammatory drugs.

The treatment of patients with rheumatoid arthritis (RA) is a challenging problem for rheumatologists. Several clinical studies have shown that antimalarials, gold salts, D-penicillamine, and some cytostatic agents have disease activity modifying properties, ${ }^{1-4}$ but the response to treatment with these drugs is variable and a certain proportion of the RA patients do not benefit. These unresponsive patients are considered to have refractory RA, an intriguing but daunting problem to the practising clinician.

Cyclosporin is a fungal peptide with unique immunosuppressive properties, inhibiting activation of both $\mathrm{B}$ and $\mathrm{T}$ lymphocytes and certain macrophage functions. ${ }^{6}$ In the clinical situation the activity of cyclosporin is highest when the drug is administered during the inductive phase of an immune response (sensitisation), i.e., at the time of organ transplantation. In animal models of autoimmune diseases, however, i.e., after sensitisation, cyclosporin also suppresses the effector phase. ${ }^{7}$ Although its action has been reported to be rever-

Accepted for publication 19 March 1986.

Correspondence to Professor A Cats, Department of Rheumatology, University Hospital, Building 1, C2Q, PO Box 9600, 2300 RC Leiden, The Netherlands. sible, studies on experimental arthritis in rat产 suggest a long lasting effect of this drug. ${ }^{8}$

These findings and the favourable results of cyclosporin treatment of other autoimmune disease $\vec{\delta}$ in $\operatorname{man}^{9}{ }^{10}$ led us to perform a double blind, placebơ controlled, multicentre study to evaluate the effi? cacy and safety of this drug in patients with. refractory RA.

\section{Patients and methods}

Patients with active and erosive definite or classicas $\mathrm{RA}$, according to the American Rheumatism $\mathrm{As}_{\overline{\mathrm{O}}}^{-}$ sociation criteria, and who had previously beep treated with antimalarials and gold salts or $D$ o penicillamine were included in the study. Further criteria for entry were anatomical and functionas stage II or III $^{11}$ and termination of corticosteroide therapy at least six months before the start of th\& study. Patients who had a history of cancer, $\mathrm{a}^{\mathrm{N}}$ serious concomitant illness, abnormal liver or renat function, or both, extra-articular manifestations of RA other than nodules, or who had undergone join\$ surgery within the preceding three months were excluded. Other exclusion criteria were: a white cel: count of less than $3000 / \mathrm{mm}^{3}\left(3 \times 10^{9} / 1\right)$, a platele 
count below $100000 / \mathrm{mm}^{3}\left(100 \times 10^{9} / \mathrm{l}\right)$, and concomitant therapy with potentially nephrotoxic drugs except non-steroidal anti-inflammatory agents.

After their informed consent had been obtained the patients were allocated randomly to either the oral cyclosporin or the placebo group, each centre having a separate list of the random allocations. The initial cyclosporin dosage was $10 \mathrm{mg} / \mathrm{kg}$ once a day given at noon for two months. If there was a satisfactory response the dosage was reduced to 7.5 $\mathrm{mg} / \mathrm{kg}$ once a day (months 3 and 4) and then to 5 $\mathrm{mg} / \mathrm{kg}$ once a day (months 5 and 6 ). The dosage was adjusted according to clinical response and side effects. Furthermore, patients were monitored on the basis of trough blood levels of cyclosporin. Blood samples for the measurement of these concentrations were drawn into heparinised tubes and stored at $4^{\circ} \mathrm{C}$ for at most one week before the cyclosporin levels were determined in whole blood by a radioimmunoassay ${ }^{12}$ performed with the kit supplied by Sandoz. If the trough blood level of cyclosporin exceeded $1000 \mathrm{ng} / \mathrm{ml}$ the dosage was adjusted, and the same volume reduction was made in the paired patient in the placebo group. In both groups administration was stopped after six months.

Non-steroidal anti-inflammatory drugs (NSAIDs) were prescribed according to individual need. In each centre one rheumatologist, who was not aware of side effects or safety parameters, assessed the joints of each of the patients of that centre monthly. The parameters of efficacy determined monthly were as follows: the duration of morning stiffness, the number of swollen joints, the Ritchie index, pain at active movement and at rest, and grip strength measured with a vigorimeter. Radiographs of hands, wrists, and feet were made at entry and after six months. Radiological abnormalities of the metacarpophalangeal and metatarsophalangeal joints and the proximal interphalangeal joints of hands and feet were graded from 0 to 4 (grade 0 : no abnormalities; grade 1: dubious erosions; grade 2: definite but mild erosions or narrowing of the joint space; grade 3: more destructive changes; and grade 4: severe erosions or ankylosis ${ }^{13}$ ), and the sum of these abnormalities was called the radiological score.

After one week and six months of cyclosporin therapy a global assessment of efficacy was made by the patient and the investigator, both of whom also made an overall assessment of efficacy at the end of the study (grades: grade 0: no effect; grade 1: slight improvement; grade 2: moderate improvement; grade 3: good improvement; grade 4: excellent improvement).

Safety and tolerability were assessed by physical examination (body weight, blood pressure, and pulse rate) and laboratory tests (cyclosporin blood levels, serum levels of creatinine and potassium, liver enzymes); these parameters were evaluated by a second doctor in each centre who was not involved in the assessment of efficacy parameters.

Table 1 Characteristics of the 36 rheumatoid arthritis patients after random allocation to the cyclosporin and placebo groups

\begin{tabular}{|c|c|c|}
\hline Parameter & $\begin{array}{l}\text { Cyclosporin group } \\
(n=17)\end{array}$ & $\begin{array}{l}\text { Placebo group } \\
(n=19)\end{array}$ \\
\hline $\begin{array}{l}\text { Sex } \\
\text { Age (years) }\end{array}$ & $\begin{array}{l}13 \mathrm{~F} / 4 \mathrm{M} \\
54 \cdot 5(12 \cdot 9 ; 24-69)^{*}\end{array}$ & $\begin{array}{l}15 \mathrm{~F} / 4 \mathrm{M} \\
55 \cdot 3(9 \cdot 7 ; 37-68)\end{array}$ \\
\hline $\begin{array}{l}\text { Duration of illness } \\
\text { (years) }\end{array}$ & $11 \cdot 8(6 \cdot 2)$ & $14.5(11 \cdot 3)$ \\
\hline Functional stage & $\begin{array}{l}\text { II }(n=12) \\
\text { III }(n=5)\end{array}$ & $\begin{array}{l}\text { II }(n=10) \\
\text { III }(n=9)\end{array}$ \\
\hline Anatomical stage & $\begin{array}{l}\text { II }(n=6) \\
\text { III }(n=11)\end{array}$ & $\begin{array}{l}\text { II }(n=8) \\
\text { III }(n=11)\end{array}$ \\
\hline
\end{tabular}

${ }^{*}$ mean (SD; range).

Table 2 Kind and frequency of side effects in both groups of rheumatoid arthritis patients in the present study

\begin{tabular}{lll}
\hline Side effects & $\begin{array}{l}\text { Cyclosporin } \\
\text { group } \\
(n=17)\end{array}$ & $\begin{array}{l}\text { Placebo } \\
\text { group } \\
(n=19)\end{array}$ \\
\hline Gastric pain & 5 & 2 \\
Nausea & 9 & 3 \\
Vomiting & 3 & 0 \\
Rise of serum creatinine level & 13 & 5 \\
Hyperkalaemia & 1 & 0 \\
Urine retention & 1 & 0 \\
Hirsutism & 3 & 0 \\
Tremor & 2 & 0 \\
Gingival hyperplasia & 3 & 0 \\
Hyperaesthesia & 5 & 1 \\
Headache & 0 & 4 \\
\hline
\end{tabular}

Table 3 Time of and reason for discontinuation of cyclosporin or placebo administration during the present study

\begin{tabular}{lll}
\hline Group & Reason & Time (weeks) \\
\hline Cyclosporin & Hyperkalaemia & 6 \\
& Non-compliance & 6 \\
& Gastrointestinal intolerance, & \\
& raised serum creatinine level & 6 \\
& Gastrointestinal intolerance & 6 \\
& Gastrointestinal intolerance & 8 \\
& Gastrointestinal intolerance & 8 \\
& No effect & 12 \\
& Rise of serum creatinine level & 19 \\
Placebo & & 2 \\
& No effect & 8 \\
& No effect & 8 \\
& No effect & 10 \\
& No effect & 16 \\
& No effect & 20 \\
\hline & Duodenal ulcer & \\
\hline
\end{tabular}


728 van Rijthoven, Dijkmans, Goei The, Hermans, Montnor-Beckers, Jacobs, Cats

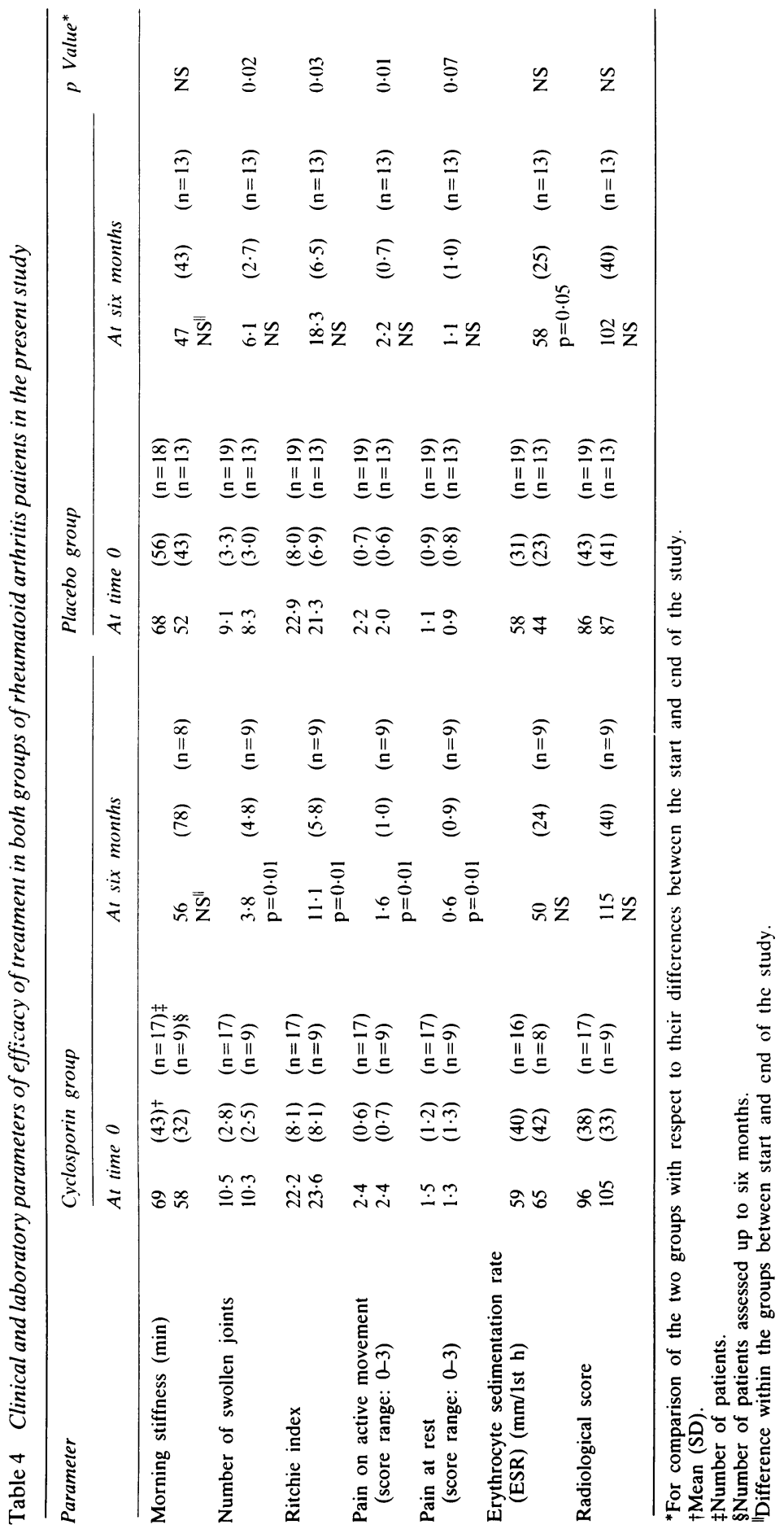


The Wilcoxon two sample test was used for statistical analysis of the data for comparison of the two groups, and the signed rank test was applied for analysis within the groups.

\section{Results}

Thirty six patients ( 28 women and eight men, mean age 54.9 years, SD 11.2 , range 24-69 years) were admitted to the study. The cyclosporin group comprised 17 patients and the placebo group 19; the demographic characteristics of the patients, which are shown in Table 1 , indicate an equal distribution over the groups. During the trial the frequency of side effects was considerable in both groups (Table $2)$. The cyclosporin group showed a highly significant $(p<0.005)$ rise of the serum creatinine level relative to the pretreatment values, the mean values for the group being 98.7 (SD 31.4) and 72.6 (SD 18.2) $\mu \mathrm{mol} / \mathrm{l}$, respectively; in two patients the rise of the serum creatinine level was judged unacceptable for continuation of cyclosporin administration (Table 3). Other reasons for withdrawing the drug in the cyclosporin group were gastrointestinal intolerance in four patients and absence of effect, hyperkalaemia, and lack of compliance, each in one patient (Table 3). In the placebo group administration was stopped in five patients because of lack of effect and in one patient who developed a duodenal ulcer (Table 3).
The findings concerning clinical, laboratory, and radiological efficacy parameters for the two groups are given in Table 4. Statistical analysis disclosed that at the start of the study the groups were comparable for each of the efficacy parameters. Further analysis was restricted to the patients who completed the six months of therapy. Comparison of the changes in both groups during the study showed significant improvement for the cyclosporin group with respect to the number of swollen joints, the Ritchie index, and pain on active movement, and pain at rest showed borderline significance (Table 4). The changes in efficacy parameters within the groups over the same period are also shown in Table 4.

As these data indicate, in the placebo group no improvement occurred in any of the parameters and the ESR was significantly higher at six months than at the start of the study. The cyclosporin group showed a non-significant decrease of the sedimentation rate (from $65 \mathrm{~mm}$ to $50 \mathrm{~mm}$ after one hour), significant improvement in the number of swollen joints, Ritchie index, and pain at both active movement and rest at six months and also less radiological progression of joint destruction, but this last was not significant relative to the placebo group.

The other parameters of efficacy and safety are given in Table 5. At the end of the study period the values for grip strength did not differ either between or within the groups. The mean score for global

Table 5 Other efficacy and safety parameters assessed in patients with rheumatoid arthritis in the present study

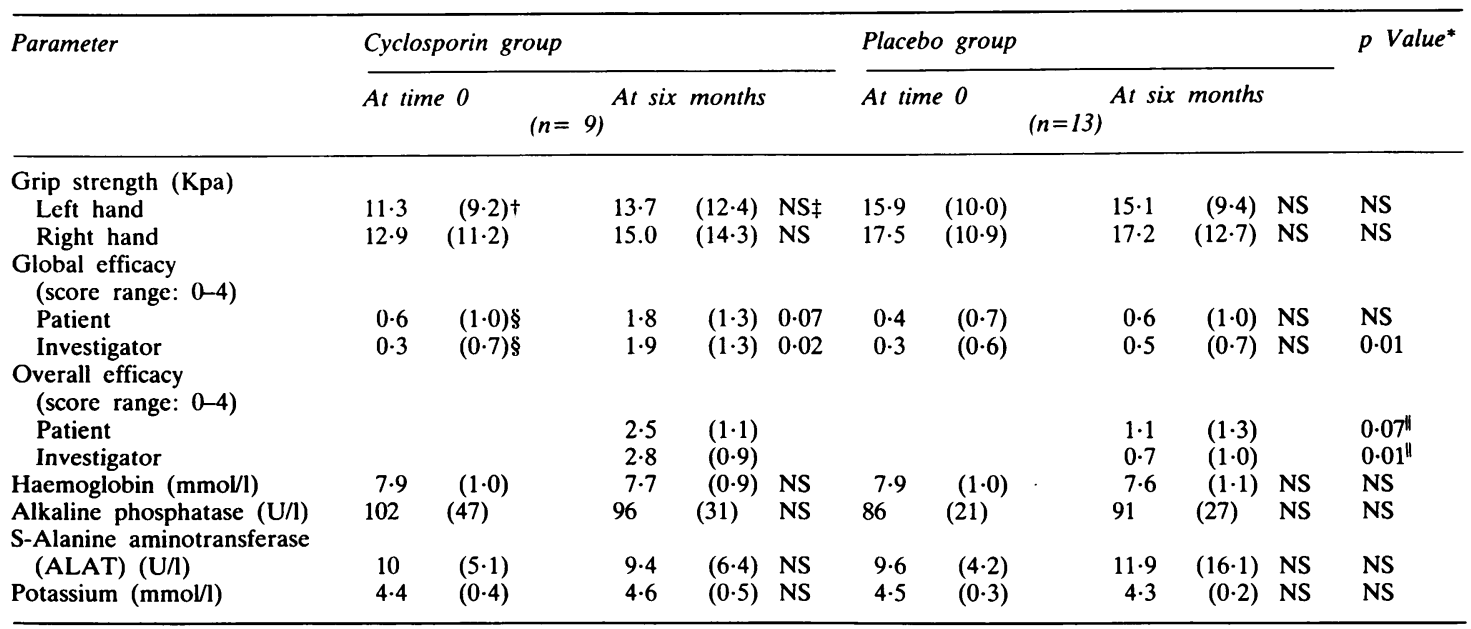

*For comparison of the two groups with respect to their differences between the start and end of the study. †Mean (SD).

$\ddagger$ Difference within group between start and end of the study.

§Measured after one week of treatment.

"Difference between the two groups at six months. 
efficacy was significantly higher for the cyclosporin group than for the placebo group at six months, as assessed by the investigator. Moreover, the score for the cyclosporin group as assessed by the investigator was significantly higher at the end of the study than at the beginning, but was the same at both time points for the placebo group. At the end of the study the score for overall efficacy as assessed by the investigator was significantly higher for the cyclosporin than the placebo group.

Mean values for haemoglobin, alkaline phosphatase, ALAT, and potassium did not change during the study either between or within the groups.

The mean value for the cyclosporin blood levels of all 17 patients treated with cyclosporin was 675 (SD 223) $\mathrm{ng} / \mathrm{ml}$.

\section{Discussion}

The main conclusion drawn from the results of this placebo controlled, double blind study is that cyclosporin improves clinically manifest symptoms, i.e., the number of swollen joints, Ritchie articular index, and pain at active movement and at rest, in patients suffering from active rheumatoid arthritis. No significant improvement in morning stiffness or laboratory parameters was found, and the placebo group showed a significant rise of the ESR. This six month study did not yield any evidence that cyclosporin can retard radiographic signs of deterioration. Reduction of radiographic progression of joint destruction, however, is by no means an effect of all 'remittive agents' or disease modifying drugs, and the only available evidence that both gold and cyclophosphamide can retard radiographic deterioration is circumstantial. ${ }^{14}$ Cyclosporin may even retain its activity after the inductive phase of the immune response in the clinical situation since it is conceivable that in rheumatoid arthritis sensitisation has already occurred.

The number of withdrawals from the study was high in both groups, but the total of five in the placebo group because of inefficacy suggests that the basis chosen for the selection of patients was good. The improvement of symptoms in the patients with active rheumatoid arthritis treated with relatively high dosages of cyclosporin should, however, be considered in the light of the adverse reactions, i.e., gastrointestinal disturbances and raised serum creatinine levels. This rise in serum creatinine proved partially irreversible (unpublished data), which is not the case for cyclosporin nephrotoxicity in renal allograft recipients. ${ }^{15}$ 16 It seems probable that the gastrointestinal and nephrotoxic reactions in our patients can be at least partially ascribed to the relatively high dosages of cyclosporin $(10 \mathrm{mg} / \mathrm{kg}$ as starting dose), which are reflected in the relativel high mean trough blood cyclosporin concentrations At present it is advised that blood levels higher that $600-800 \mu \mathrm{g} / \mathrm{ml}$ should be avoided for cyclosporifo treated patients with an autoimmune disease. Moreover, the concomitant treatment with NSAID? might have led to gastrointestinal disturbances ancf nephrotoxicity. Besides nephrotoxicity due tœ NSAIDs, ${ }^{18}$ the kidney in rheumatoid arthritiह patients can be directly involved owing to the disease. ${ }^{19}$ An increased incidence of disturbances of the upper gastrointestinal tract in rheumatoid arthri $\vec{\varpi}$ tis patients has been reported, but it is not cleap whether this is related to the drug treatment o 5 represents a systemic manifestation of the disease. ${ }^{26}$

In summary, cyclosporin proved to be more effective than placebo during a six month treatmenk period in patients with rheumatoid athritis refraco tory to more conventional drugs. The observeff adverse affects may have been dose related and

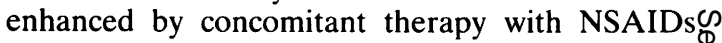
Thus cyclosporin seems to be an effective disease modifying drug in rheumatoid arthritis, provided i⿱ is given in a daily dose not exceeding $5 \mathrm{mg} / \mathrm{kg}$ and io well monitored, with blood trough levels not ex= ceeding $500 \mathrm{ng} / \mathrm{ml}$. Moreover, to avoid nephrotgx $\vec{\oplus}_{\infty}$ icity we recommend the omission of concomitan administration of NSAIDs with the possible excep tion of sulindac, which is claimed to give less reña dysfunction. $^{21}$

Cyclosporin was kindly provided by Sandoz B V, Uden, Th\& Netherlands. The blood concentrations of cyclosporin were deter $=$ mined by Dr A J Moolenaar (Leiden, The Netherlands) and Dr Gijssen (Heerlen, The Netherlands). The authors are greatly indebted to Anita Postma for typing the manuscript.

\section{References}

1 Hamilton E B D, Scott J T. Hydroxychloroquine sulfate (Plaquenil) in treatment of rheumatoid arthritis. Arthritis Rheum 1962; 5: 502-12.

2 Sigler J W. Bluhn G B, Duncan H, Sharp J T, Ensign D Cं McCrum W R. Gold salts in the treatment of rheumatoif arthritis: a double-blind study. Ann Intern Med 1974; 80: 21-6.

3 Berry H, Liyanage R, Durance C G, Barnes C G, Berger LO Trial comparing azathioprine and penicillamine in treatment of rheumatoid arthritis. Ann Rheum Dis 1976; 35: 542-3.

4 Weinblatt M E, Colblyn J S, Fox D A, et al. Efficacy of low-dose methotrexate in rheumatoid arthritis. $N$ Engl $J$ Med 1985; 312: 818-22.

5 Klippel J H, Decker J C. Methotrexate in rhcumatoid arthritis. $N$ Engl J Med 1985; 312: 853-4.

6 Hess A D, Tutschka P J, Pu Z, Santos G W. Effect o $\$$ J cyclosporin $A$ on human lymphocyte responses in vitro. IVO Production of $T$ cell stimulatory growth factors and developo ment of responsiveness to these growth factors in CyA-treated primary MLR cultures. J Immunol 1982; 128: 360-7.

7 Borel J F. Cyclosporin A. Present experimental status. Trans ${ }^{+}$ plant Proc 1981; 13: 344-8.

8 Henderson B, Staines N A, Burrai I, Cox J H. The anti-arthritio and immunosuppressive effects of cyclosporine on arthritio 
induced in the rat by type II collagen. Clin Exp Immunol 1984; 57: 51-6.

9 Nussenblatt R B, Palestine A G, Chan C C, Mochizuki M, Yancey K. Effectiveness of cyclosporine therapy for Behçet's disease. Arthritis Rheum 1985; 28: 671-9.

10 Stiller C R, Dupré J, Gent M, et al. Effects of cyclosporin immunosuppression in insulin-dependent diabetes mellitus of recent onset. Science 1984; 223: 1362-7.

11 Steinbrocker O, Traeger C H, Batterman R C. Therapeutic criteria in rheumatoid arthritis. JAMA 1949; 140: 659-62.

12 Donatsch $P$, Abisch $E$, Homberger $M$, Traber $R$, Trapp $M$, Voges $R$. A radioimmunoassay to measure cyclosporin $A$ in plasma and serum samples. J Immunoassay 1981; 2: 19-32.

13 Kellgren J H, ed. The epidemiology of chronic rheumatism. Oxford: Blackwell Scientific, 1963. (Atlas of standard radiographs of arthritis; Vol 2).

14 Iannuzzi L, Dawson N, Zein N, Kushner I. Does drug therapy slow radiographic deterioration in rheumatoid arthritis? $N$ Engl J Med 1983; 309: 1023-8.

15 Chapman J R, Griffiths D, Harding N G L, Morris P J. Reversibility of cyclosporin nephrotoxicity after three months' treatment. Lancet 1985; i: 128-9.
16 Henny F C, Kleinbloesem C H, Moolenaar A J, Paul L C, Breimer D D, Van Es L A. Pharmacokinetics and nephrotoxicity of cyclosporin A in renal transplant recipients. Transplantation (in press).

17 Von Graffenried B, Harrison W B. Cyclosporin in autoimmune diseases-side effects (with emphasis on renal dysfunction) and recommendations for use. In: Schindler R, ed. Cyclosporin in autoimmune diseases. Berlin: Springer, 1985, 59-73.

18 Kimberly R P, Bowden R E, Keiser H R, Plotz P H. Reduction of renal function by newer anti-inflammatory drugs. Am J Med 1978; 64: 804-7.

19 Breedveld F C, Valentijn R M, Westedt M-L, Weening J J. Rapidly progressive glomerulonephritis with glomerular crescent formation in rheumatoid arthritis. Clin Rheumatol 1985; 4: 353-9.

20 Sun D C, Roth S H, Mitchell C S, England D W. Upper gastrointestinal disease in rheumatoid arthritis. Am J Dig Dis 1974; 19: 405-10.

21 Ciabattoni G, Cinotti G A, Peirucci A, et al. Effects of sulindac and ibuprofen in patients with chronic glomerular disease. $N$ Engl J Med 1984; 310: 279-83. 